\title{
Resolution Dependence in Modeling Extreme Weather Events
}

\author{
John Taylor, ${ }^{1,2}$ Jay Larson ${ }^{1}$ \\ ${ }^{1}$ Mathematics \& Computer Science, Argonne National Laboratory, Argonne, Illinois 60439 \\ ${ }^{2}$ Environmental Research Division, Argonne National Laboratory, Argonne, Illinois 60439 \\ $\{$ jtaylor larson\}@mcs.anl.gov \\ http://www-climate.mcs.anl.gov/
}

\begin{abstract}
At Argonne National Laboratory we have developed a high performance regional climate modeling simulation capability based on the NCAR MM5v3.4. The regional climate simulation system at Argonne currently includes a Java-based interface to allow rapid selection and generation of initial and boundary conditions, a high-performance version of MM5v3.4 modified for long climate simulations on our 512-processor Beowulf cluster (Chiba City), an interactive Web-based analysis tool to facilitate analysis and collaboration via the Web, and an enhanced version of the CAVE5d software capable of working with large climate data sets. In this paper we describe the application of this modeling system to investigate the role of model resolution in predicting extreme events such as the "Hurricane Huron" event of 11-15 September 1996. We have performed a series of "Hurricane Huron" experiments at 80,40, 20, and $10 \mathrm{~km}$ grid resolution over an identical spatiotemporal domain. We conclude that increasing model resolution leads to dramatic changes in the vertical structure of the simulated atmosphere producing significantly different representations of rainfall and other parameters critical to the assessment of impacts of climate change.
\end{abstract}

\section{Introduction}

In a recent IPCC report on The Regional Impacts of Climate Change it was concluded:

The technological capacity to adapt to climate change is likely to be readily available in North America, but its application will be realized only if the necessary information is available (sufficiently far in advance in relation to the planning horizons and lifetimes of investments) and the institutional and financial capacity to manage change exists. [1]

IPCC also acknowledged that one of the key uncertainties that limit our ability to understand the vulnerability of subregions of North America to climate change and to develop and implement adaptive strategies to reduce vulnerability was the need to develop accurate regional projections of climate change, including extreme events [1]. In particular, we need to account for the physical-geographic characteristics that play a significant role in the North American climate (e.g., the Great Lakes, coastlines, and mountain ranges) and also properly account for the feedbacks between the biosphere and atmosphere [1].

V.N. Alexandrov et al. (Eds.): ICCS 2001, LNCS 2073, pp. 204-211, 2001.

Springer-Verlag Berlin Heidelberg 2001 
The potential impacts of global climate change have long been investigated based on the results of climate simulations using global climate models with typical model resolutions of the order of hundreds of kilometers [2,3]. However, the assessment of the impacts of climate change at the regional and local scales requires predictions of climate change at the 1-10 kilometer scale. Model predictions from global climate models with such high resolutions are not likely to become widely available in the near future.

Accordingly, at Argonne National Laboratory we have begun developing a regional climate simulation capability for high-performance computers with the longterm goal of linking the predictive global climate modeling capability with the impact assessment and policymaking communities. The primary technical challenge is to downscale global climate model output to the regional scale. Our focus area is the Midwest region of the United States.

\section{Argonne Regional Climate Simulation System}

The regional climate simulation system at Argonne currently includes

- a Java-based interface to allow rapid selection and generation of initial and boundary conditions,

- a high-performance version of MM5v3.4 modified to enable long climate simulations on the Argonne Chiba City 512 -processor (500 MHz Pentium III) Beowulf cluster,

- an interactive Web-based analysis tool to facilitate analysis and collaboration via the Web, and;

- an enhanced version of the CAVE5d software capable of working with large climate data sets.

The model used in this study is the Pennsylvania State University/National Center for Atmospheric Research (PSU/NCAR) fifth-generation mesoscale model (MM5). In brief, MM5 is a three-dimensional, nonhydrostatic, elastic mesoscale model. It uses finite differences and a time-splitting scheme to solve prognostic equations on an Arakawa type-B staggered grid. Its vertical coordinate, though defined as a function of the reference-state pressure, is similar to a terrain-following coordinate. For case studies, MM5 employs observed wind, temperature, and humidity as the initial and boundary conditions and incorporates realistic topography and sophisticated physical processes to represent the appropriate forcing for the development of the observed weather system. These physical processes include clouds, long- and shortwave radiative processes, and surface fluxes of heat, moisture, and momentum. A more detailed description of MM5 is provided by Chen and Dudhia [4], Chen et al. [5], Dudhia [6], and Grell et al. [7] .

The NCAR MM5 modeling system consists of six programs: TERRAIN, REGRID, RAWINS, INTERP, GRAPH, and MM5 [4]. Each of the programs is executed in the above order interdependently. They are composed of a series of scripts that traditionally have been time consuming to modify and execute; recently, however, this process has been simplified by the use of the Java Regional Climate 
Workbench, developed at Argonne by Mathematics and Computer Science Division staff, including John Taylor, Veronika Nefedova and Kevin Reitz [8].

To facilitate research collaboration, we have developed a Web-based application tool that enables access via a Web browser to the output of regional climate model runs using the MM5 system. Figure 1 illustrates a typical session. The Web browser uses the native MM5 data format, thus avoiding the need to store duplicate copies of model output, and works efficiently with gigabytes of data. The Web tool was developed by using IDL/ION software. An enhanced version of this Web tool is currently under development.

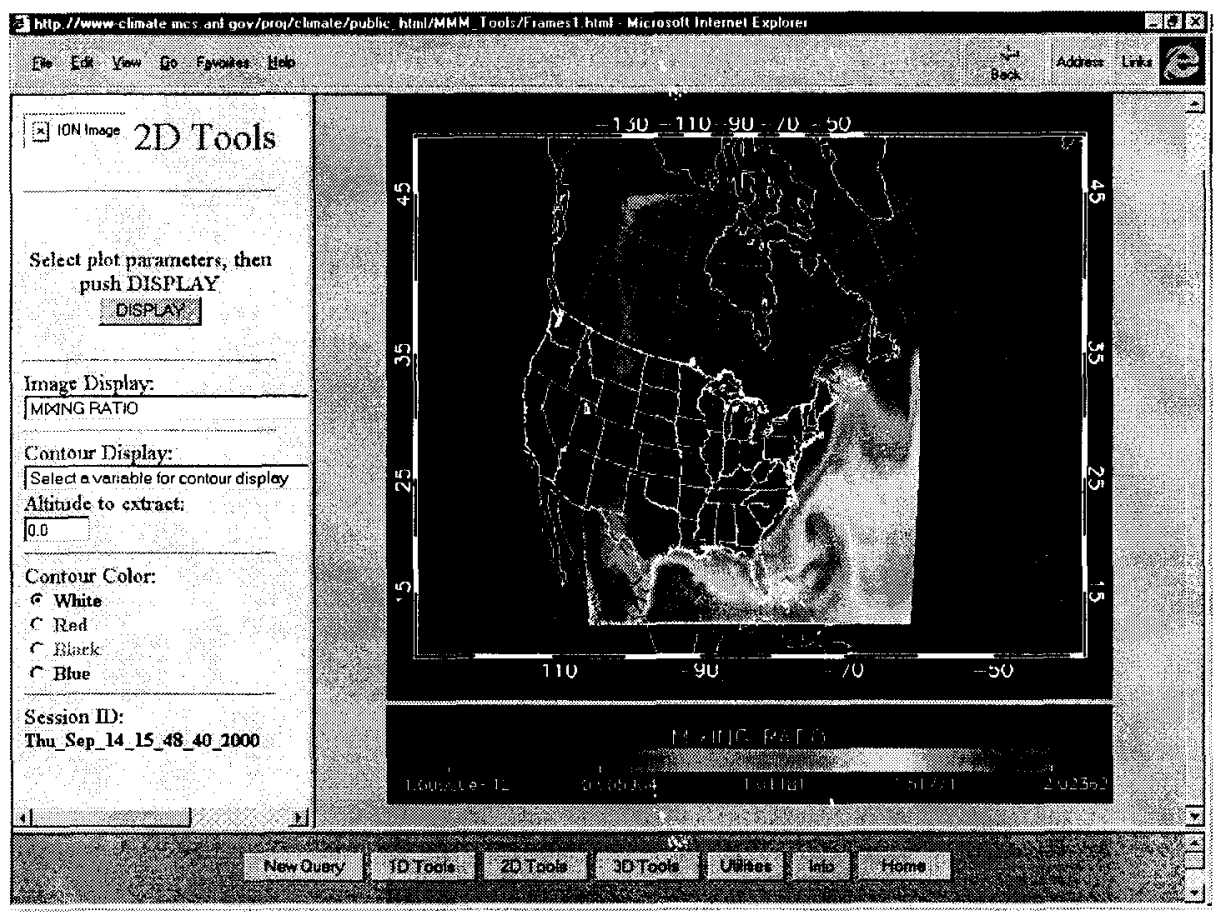

Fig. 1. Web interface displaying the water vapor mixing ratio data from a "Hurricane Huron" simulation. All plots are computed online as required.

\section{3 "Hurricane Huron" Event}

An intense cutoff low developed over the Great Lakes region during the period 11-15 September 1996.The system eventually developed an eye over Lake Huron and spiral convection bands producing intense rainfall and wind speeds in excess of $75 \mathrm{mph}$. While over Lake Huron the low pressure system intensified, with lake surface temperatures observed to fall $4-5^{\circ} \mathrm{C}$ during this period. Given the similarity in appearance in satellite photographs to a hurricane and to the process of development to a hurricane, this unique Great Lakes weather event was termed "Hurricane Huron" [9]. 


\section{Model Results}

We have performed preliminary model runs in climate mode using the latest release of the MM5 modeling system (V3.4) looking at extreme events. Mesoscale resolution climate models provide a consistent framework for us to investigate the link between incoming solar radiation, climate and extreme weather. A series of experiments were undertaken in order to illustrate the importance of enhanced model resolution to simulating the weather, climate, and atmospheric transport processes that will affect extreme weather events.

In this paper we report the results of our model simulations of "Hurricane Huron." We have performed four simulations for the period 6-15 September 1996, at a range of model grid resolutions, $80,40,20$, and $10 \mathrm{~km}$ over an identical $2000 \times 2000$ $\mathrm{km}$ region centered over Lake Huron. By performing our model simulation over an identical spatiotemporal domain we can study the effect of grid resolution on the evolution of the model simulation. We use NCAR/NCEP Reanalysis Project wind fields to provide boundary and initial conditions.

'Hurricant Huran' at 80x60 km Grid Resolution

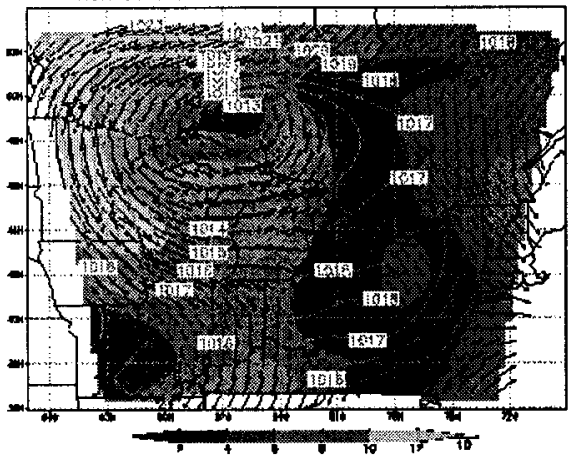

'Hurricane Huron' ot $40 \times 40 \mathrm{~km}$ Grid Resolution

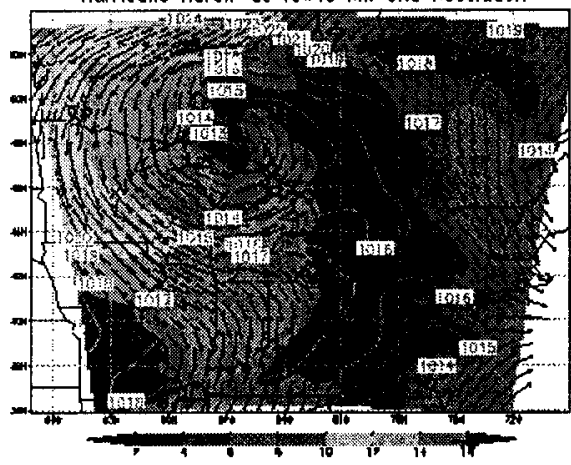

'Hurricana Huron' at $20 \times 20 \mathrm{~km}$ Grid Ranolution

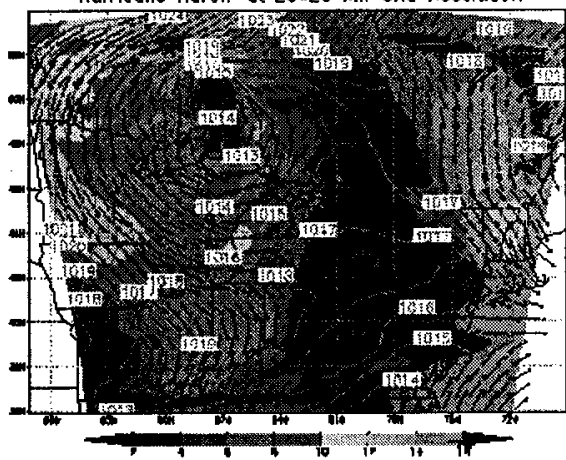

'Hurricang Huron' of $10 \times 10 \mathrm{~km}$ Grid Resolution

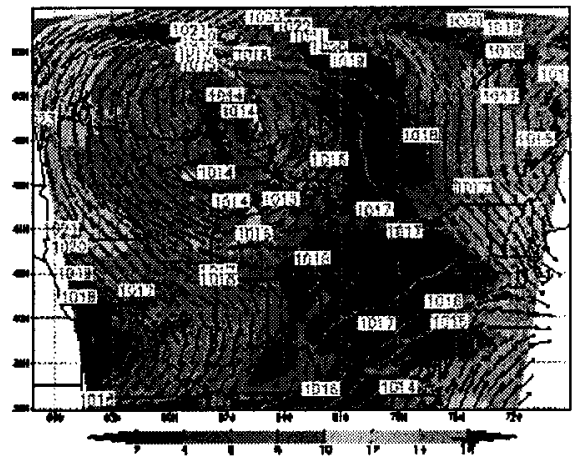

Fig. 2. Wind speed and surface pressure for hour ending $12 Z 11$ September 1996 at $80,40,20$, and $10 \mathrm{~km}$ grid resolution. Wind speeds intensify, and the formation of a better-defined eye of the low-pressure system is evident as we go to higher model grid resolutions. 
Figure 2 illustrates the results of modeling an intense cutoff low that developed over the Great Lakes region during the period 11-15 September 1996. In the model simulations the low-pressure system eventually developed an eye, with spiral convection bands producing intense rainfall and high wind speeds. The color contour intervals show that the wind speed and the contour intervals are identical for all simulations. Arrows represent wind speed and direction and, for clarity, have been plotted at the $80 \mathrm{~km}$ grid resolution only, for all plots. Wind speeds increase by up to a factor of 2 as we increase grid resolution from 80 to $10 \mathrm{~km}$. Figure 3 illustrates that hourly rainfall intensity increases dramatically, by nearly an order of magnitude, as we go to higher model resolutions. The pattern of rainfall also changes from broadscale, low-intensity rainfall at $80 \mathrm{~km}$ grid resolution to high-intensity rainfall with significant spatial structure associated with formation of rain bands.
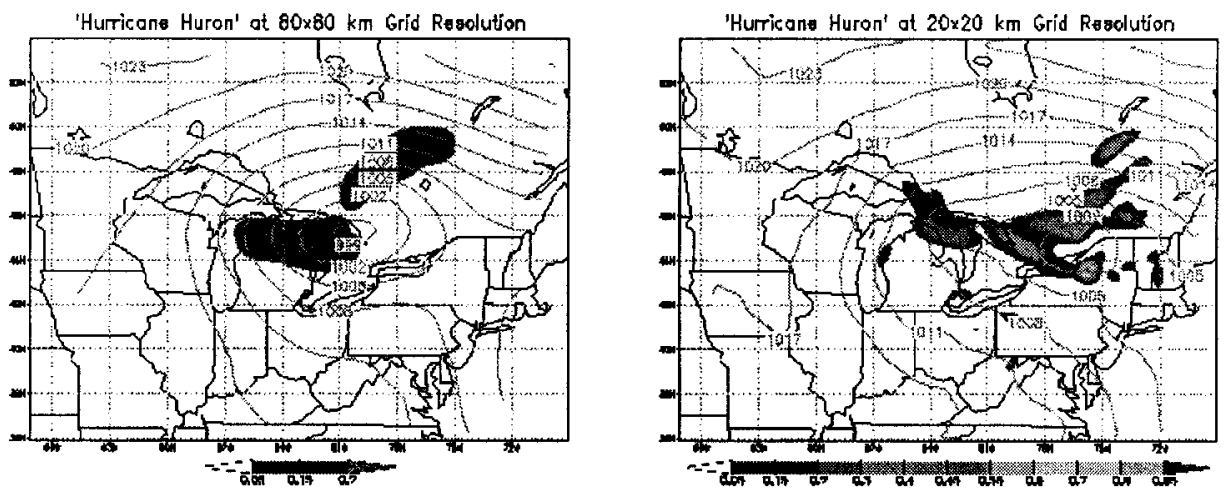

'Hurricans Huron' of $40 \times 40 \mathrm{~km}$ Grid Regelution

'Hurricane Huron' at $10 \times 10 \mathrm{~km}$ Grid Rosolution
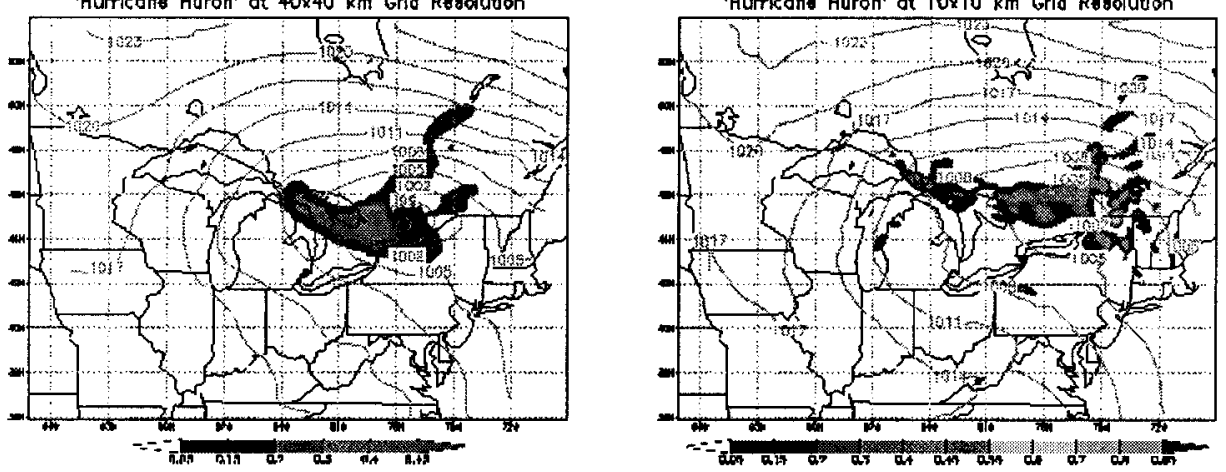

Fig. 3. Precipitation and surface pressure for hour ending $12 Z 11$ September 1996 at 80, 40, 20, and $10 \mathrm{~km}$ grid resolution. Precipitation intensifies by nearly an order of magnitude as we go to higher model resolutions and occupies a smaller more sharply defined rainbands. Increasing precipitation intensities will alter the faction of rainfall allocated to storage in the soil (i.e., soil moisture and runoff), which in turn will alter rates of decomposition and photosynthesis, particularly under water-limited conditions. 

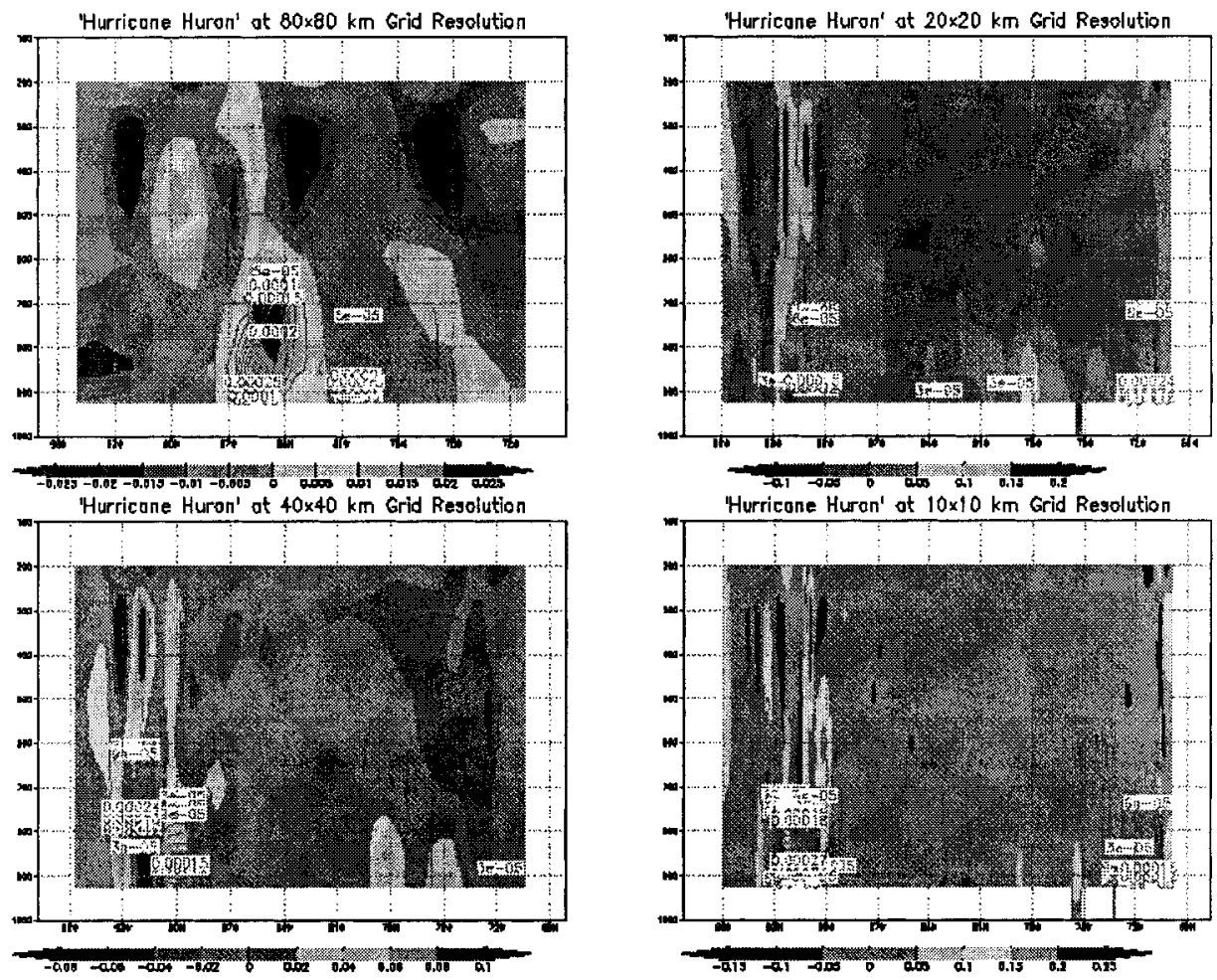

Fig. 4. Vertical velocities (hPas ${ }^{-1}$ ) for the hour ending $12 Z 11$ September 1996 at $80,40,20$, and $10 \mathrm{~km}$ grid resolution at $45^{\circ} \mathrm{N}$. Vertical velocities intensify by more than an order of magnitude and penetrate to much greater height in the atmosphere as we go to higher model resolutions, and they occupy a more sharply defined regions.

We note that the scales on the graphs in Fig. 4 increase by an order of magnitude in going from 80 to $10 \mathrm{~km}$ grid resolution. Figure 4 indicates that changes in vertical velocities associated with the higher model resolution probably plays an important role in the simulation of the precipitation events presented in Fig. 3. As with precipitation, vertical velocities increase dramatically with increasing grid resolution. We also see the appearance of greater structure in the vertical motions in the atmosphere, in that broad-scale vertical motions at $80 \mathrm{~km}$ grid resolution are replaced by much more sharply defined, intense vertical motions associated with zones of strong convergence and divergence. This implies that at higher resolutions we are able to better simulate the formation and evolution of rain bands typically associated with such extreme events as "Hurricane Huron." The substantial differences in vertical motions between the simulations at different grid resolutions also has important implications for the study of atmospheric chemistry and to the application of inverse methods to the study of the sources and sinks of greenhouse gases, where vertical motions help determine the concentration of trace gases. 


\section{Conclusion and Future Research}

We have performed preliminary model runs at $80,40,20$, and $10 \mathrm{~km}$ grid resolution in climate mode using the latest release of the MM5 modeling system (V3.4) simulating the extreme Midwest weather event "Hurricane Huron." We conclude that model resolution has played an important role in determining the key parameters typically used to determine the impact of extreme weather events, such as wind speeds and precipitation rates. Model resolution was also found to have a significant impact on atmospheric vertical motions, affecting precipitation rates and their spatial distribution. Changes in vertical motions with increasing grid resolution could also play a significant role in simulations of atmospheric chemistry and inverse modeling aimed at determining the sources and sinks of greenhouse gases.

We will continue to address the key scientific and computational issues in regional climate modeling [10] and their importance to simulating the climate of the US Midwest, including

- defining and delivering high-quality data products via the Web,

- improving the performance of long-term regional climate simulations, and

- assessing the quality of GCM ipputs and the role ofmodel spinup and climate drift on regional climate simulations.

We also plan to assess the importance of consistent physics, the sensitivity of climate to the lateral boundary conditions, and the effect of two-way nesting. Finally, the model must be enhanced to include better representation of agriculture (particularly corn and wheat in the U.S. Midwest), natural ecosystems, atmospheric chemistry and biogeochemical cycles of the key greenhouse gases, and the role of the oceans and lakes.

\section{Acknowledgments}

We thank the many staff at the Mathematics and Computer Science Division at Argonne National Laboratory in Argonne, Illinois, who assisted us in developing the regional climate simulation capability. This work was supported in part by the Office of Biological and Environmental Research, U.S. Department of Energy, under Contract W-31-109-Eng-38.

\section{References}

1. IPCC (1998) The Regional Impacts of Climate Change, Cambridge Univ. Press, Cambridge.

2. IPCC WGI (1990) Climate Change: The IPCC Scientific Assessment. R. A. Houghton et al. (eds.), Cambridge Univ. Press, Cambridge, UK. 
3. IPCC WGI (1996) Climate Change 1995: The Science of Climate Change R.A. Houghton et al. (eds.).,Cambridge Univ. Press, Cambridge, UK.

4. Chen, F. and Dudhia, J. (2001) Coupling an Advanced Land-Surface/Hydrology Model with the Penn State/NCAR MM5 Modeling System, Part I: Model implementation and Sensitivity, Monthly Weather Review, in press. See also Pennsylvania State University / National Center for Atmospheric Research, MM5 Home Page http://ww.mmm.ucar.edu/mm5/mm5-home.html.

5. Chen, F., K. Mitchell, J. Schaake, Y. Xue, H. L. Pan, V. Koren, Q. Y. Duan, K. Ek, and A. Betts (1996) Modeling of Land-Surface Evaporation by Four Schemes and Comparison with FIFE Observations. J. Geophys. Res., 101, 7251-7268.

6. Dudhia, J. (1993) A Nonhydrostatic Version of the Penn State / NCAR Mesoscale Model: Validation Tests and Simulation of an Atlantic Cyclone and Cold Front. Mon. Wea. Rev., 121, 1493-1513.

7. Grell, G. A., J. Dudhia, and D. R. Stauffer (1994) The Penn State/NCAR Mesoscale Model (MM5). NCAR Technical Note, NCAR/TN-398+STR, 138 pp.

8. Taylor, J. (2000) Argonne National Laboratory, Climate Workbench http://wwwclimate.mcs.anl.gov/proj/climate/public_html/climate-workbench.html.

9. Miner, T., P. Sousounis, G. Mann, and J. Wallman, "Hurricane Huron," Bulletin of the American Meteorological Society, February.

10. Giorgi, F., and L. O. Mearns (1999) Introduction to Special Section: Regional Climate Modeling Revisited, J. Geophysical Research, 104, 6335-6352. 